\title{
Thermal protective uniforms and hoods: impact of design modifications and water content on burn prevention in New York City firefighters: laboratory and field results
}

\author{
D J Prezant, K S Malley, R L Barker, C Guerth, K J Kelly
}

\begin{abstract}
Objectives-To determine (1) the effectiveness of hoods in reducing head burns, (2) the impact of clothes worn under the protective outer uniform (modern $=$ long sleeve shirt and long pants; modified modern $=$ short sleeve $\mathbf{T}$-shirt and short pants) on burns, and (3) whether water content (dry, damp or saturated) affects the level of thermal protection.

Setting-Fire Department of the City of New York (FDNY).

Methods-Laboratory tests (fully dressed manikin) evaluated the different uniform and water conditions when exposed to an average $24 \mathrm{cal} / \mathrm{cm}^{2}$ heat flux, approximately $2250^{\circ} \mathrm{F}$ air temperature. FDNY field results compared (1) head burns during winters wearing the hood to winters without hood and (2) upper and lower extremity burns during summers wearing traditional, modern, and modified modern uniforms.
\end{abstract}

Results-Laboratory tests showed that thermal protection was: (1) dramatically improved by the hood with protection increasing as water content increased and (2) not significantly different between modern and modified modern uniforms, regardless of water content. FDNY field results confirmed these tests showing (1) significant decreases in neck burns (by $54 \%$ ), ear burns (by $60 \%$ ), and head burn totals (by $46 \%$ ) wearing the hood and (2) no significant differences in upper or lower extremity burns wearing modern compared with modified modern uniforms.

Conclusions-Based on combined laboratory and field results, we strongly recommend the use of modern thermal protective hoods and the modified modern uniform.

(Injury Prevention 2001;7(Suppl I):i43-49)

Keywords: firefighting uniforms; burn prevention; thermal injury evaluation; occupational injury

The Fire Department of the City of New York (FDNY) is the largest fire department in the United States, with over 11000 firefighters, and one of the most active, averaging over 2500 structural fires per month. In an effort to reduce burns, FDNY reoutfitted to a modern fire protective uniform during the latter half of
1994. Modern uniform includes protective overcoat and overpants while the traditional uniform includes only overcoat. Modern uniforms also meet or exceed National Fire Protection Association (NFPA) recommendations for structural firefighting ${ }^{1}$ using improved thermal protective textiles that suffer little damage until temperatures far exceed that needed to decompose cotton, $250^{\circ} \mathrm{C} .^{2-4}$

When the first year wearing FDNY's modern uniform (1995) was compared with the last full year wearing FDNY's traditional uniform (1993), lower extremity burns decreased by $86 \%$ (from 419 to 57 ) and upper extremity burns decreased by $75 \%$ (456 to 114$).^{5}$ Risk exposure (that is, structural and serious fires) was not significantly different in 1993 (31 497 and 3806) and 1995 (30191 and 3960). The success of the modern uniform in reducing upper and lower extremity burns served to highlight several remaining issues. First, head burns (scalp, ears, face, and neck) were not similarly reduced. Head burns decreased by only 39\% (from 610 in 1993 to 374 in 1995) and their numbers exceeded the total number of burns to all other anatomic locations. Second, firefighters found the modern uniform, worn over a long sleeve shirt and long pants, to be uncomfortably restrictive (especially when wet) at the elbows and knees.

In response to these issues, FDNY outfitted firefighters with thermal hoods for head protection and, given the modern uniform's improved thermal protection to upper and lower extremities, allowed the use of short sleeve T-shirts and short pants worn underneath. The purpose of this study was to determine the impact of the thermal hood and a modified modern uniform (short sleeve shirt and short pants) on burns. Laboratory predictions and FDNY field results were analyzed. As the uniform in real firefighting situations is never dry, the impact of water content (dry, damp, saturated) was evaluated before field tests using a fully dressed, instrumented, manikin during a $12 \mathrm{sec}$ exposure averaging $2.0 \mathrm{cal} /$ $\mathrm{cm}^{2} / \mathrm{sec}$ at approximate air temperatures of $2250^{\circ} \mathrm{F}^{3}$ Field results compared FDNY (1) head burns with and without the hood and (2) upper and lower extremity burns wearing three different uniforms: traditional (long sleeve shirt and long pants worn underneath), modern (long sleeve shirt and long pants worn underneath), and modified modern (short sleeve T-shirt and short pants worn underneath). 


\section{Methods}

FDNY HEAD PROTECTION

The hood, worn by FDNY firefighters since January 1996, is made of double layer porous knit $(20 \%$ polybenzimidazole (PBI), 80\% Lenzing rayon) with a crown vent and bib-like design that provides coverage for scalp, ears, forehead, cheeks, chin, jaw, and neck (Total Fire Inc, Dayton, Ohio). This hood is compliant with NFPA standard \#1971. ${ }^{1}$ As per FDNY regulations, additional protection is provided to the scalp, ears, and rear of the neck by a helmet worn with earflaps turned down and overcoat worn with collar turned up. Uncovered areas (lower forehead, eyes, nose, and mouth) are fully covered when the hood is worn over the self contained breathing apparatus (SCBA) mask.

\section{FDNY TRADITIONAL UNIFORM}

The traditional uniform used before 1995 consisted of helmet, SCBA apparatus mask and cylinder, protective overcoat, gloves, and high boots. The overcoat (model FDNY BC-1/ TC-6, Morning Pride, Dayton, Ohio) consisted of outer shell made of $7.5 \mathrm{oz}$ Nomex III, a Goretex moisture barrier stitched on $100 \%$ Nomex III, and inner thermal liner Aralite $100 \%$ Aramid quilt stitched $7.5 \mathrm{oz} / \mathrm{sq} \mathrm{yd}$. Under this uniform, FDNY firefighters wore long sleeve shirt and long pants made of flame resistant $60 \%$ polyester $/ 40 \%$ cotton.

FDNY'S MODERN UNIFORM

The modern uniform consists of protective overcoat, overpants, gloves, and short boots. Both protective overgarments are made of the same materials consisting of an outer shell of $60 \%$ Kevalar Aramid $/ 40 \%$ PBI, a 1.2 oz Crosstech moisture barrier laminated to $2.7 \mathrm{oz}$ Nomex E-89 base and inner thermal liner 8 oz/sq yd quilted three layer E-89 fabric (FDNY Bunker Gear, Total Fire Inc). Overpants normally feature a level 2 kneepad (multiple layers E-89 quilt and Crosstech).

FDNY MODIFIED MODERN UNIFORM

The modified modern uniform differed from the modern uniform by substituting a work short sleeve T-shirt and work short pants (both $100 \%$ cotton) for long sleeve shirt and long pants (both flame resistant $60 \%$ polyester $/ 40 \%$ cotton).

PYROMAN THERMAL PROTECTIVE PERFORMANCE CLOTHING ANALYSIS SYSTEM

This system is an adult male manikin with 122 heat sensors (thermocouple embedded below the surface of an epoxy molded cone) individually calibrated to insure accurate temperature readings and calculation of surface heat flux. A computer controlled flash fire uses eight industrial propane gas torches carefully positioned and modified to create a controlled volume of fire that fully engulfs the manikin. In this study, heat flux was set at an average $2.0 \mathrm{cal} / \mathrm{cm}^{2} / \mathrm{sec}$ (approximate air temperature $2250^{\circ} \mathrm{F}$ ) for a 12 second exposure simulating flashover fires. Heat flux equaled NFPA standard \#1971 specifications for thermal protective performance testing ${ }^{1}$ and exposed the manikin to radiant and convective heat. ${ }^{6-8} \mathrm{~A}$ computerized data acquisition unit (Hewlett Packard) scanned and recorded each sensor's temperature every $0.5 \mathrm{sec}$. Temperature readings, along with a one dimensional transient heat conduction model, were used to compute heat flux experienced at the sensor's surface over time. The PyroMan system predicts burn injury by using Henrique's model to translate instrument readings into human tissue damage..$^{6-8}$ During PyroMan tests, FDNY's complete modern uniform ensemble was worn as described except SCBA mask was worn without SCBA cylinder. Consistent with FDNY regulations, hood was worn over SCBA mask and helmet was worn over hood with earflaps turned down and protective overcoat collar turned up. A thermal protective performance report was generated which included burn(s) location and severity (second or third degree).

Total head burn score and individual location scores were computed based on the number of sites on the manikin's head, assuming equal weight for all sites. To evaluate the hood, seven thermocouple instrumented areas were identified (left ear, right ear, left face, right face, front neck, rear neck, and scalp). To evaluate the uniform, 10 thermocouple instrumented areas were identified (front torso, rear torso, shoulder, scapula, upper arm, mid-arm, lower arm, upper leg, mid-leg, and lower leg). For each site, a second degree burn received two points and a third degree burn received three points.

WATER CONTENT LABORATORY TESTS

PyroMan Hood tests evaluated four conditions (none, dry, damp, or saturated hood). Damp corresponds to hood water content found after responding to a fire scene but before hose line operations. Before carrying out these tests, 18 FDNY firefighters dressed in modern uniform with hood went through simulated firefighting operations at moderate to high work intensity for an average 17 minutes. Hose lines were not charged with water so hood weight gain was due to sweat. Hood weight gain averaged 30.2 $\mathrm{g}$ (range 16.6 to $58.8 \mathrm{~g}$ ) for an increase averaging $22 \%$ (range $13 \%$ to $51 \%$ ). Damp condition was created by fine spraying $30 \mathrm{~g}$ water over the hood outer surface. Saturated condition corresponds to hood water content after firefighting (water source $=$ body sweat and hose line). Saturation was created by a two minute immersion of the hood in water (without postimmersion blotting). For PyroMan uniform tests, it was difficult to predict extent and specific location of water absorption for each clothing layer. Thus, four conditions were tested: modern uniform dry, modern uniform saturated, modified modern uniform dry, and modified modern uniform saturated. Saturated defined as a two minute immersion of the work shirt and pants in water (without postimmersion blotting), thermal liner was fine sprayed moist to touch and outer shell sprayed dripping wet. 


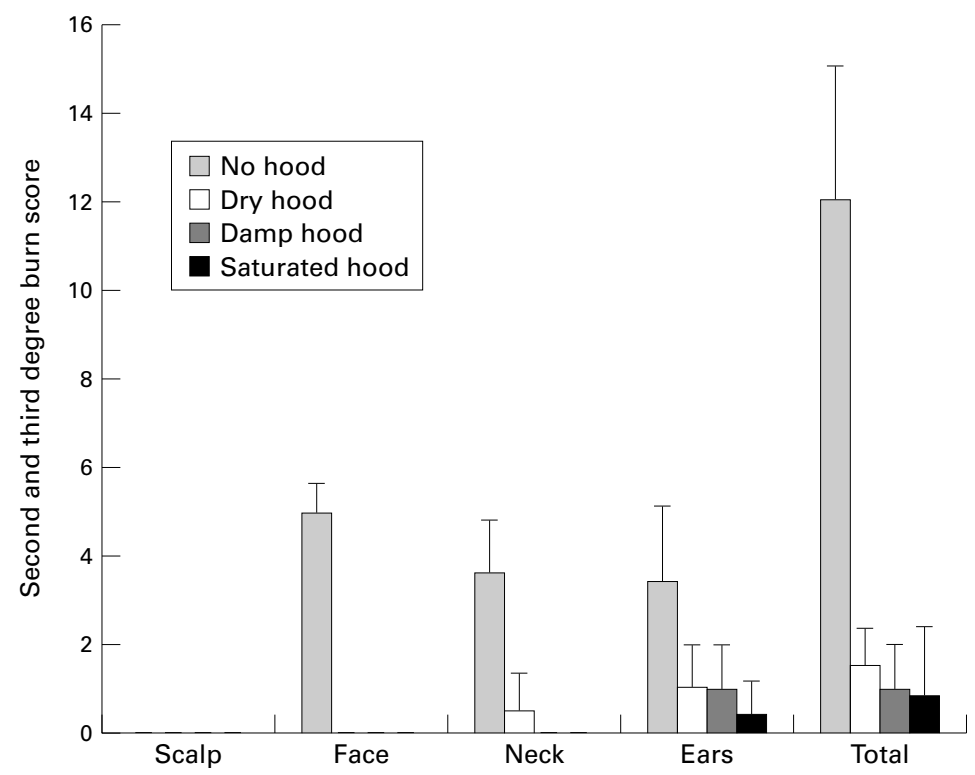

Figure 1 Predicted head burn scores (mean, SD) by location was measured using PyroMan Thermal Protective Clothing Analysis System following a $2.0 \mathrm{cal} / \mathrm{cm}^{2} / \mathrm{sec}$ exposure for $12 \mathrm{sec}$ under four hood conditions: none $(n=5)$, dry $(n=4)$, damp $(n=4)$, and saturated $(n=5)$. Burn score for each site equals sum of second degree burns $\times 2+$ sum of third degree burns $\times 3$. For all conditions, no scalp burns were recorded due to coverage by the helmet. Number of head burns and burn score was significantly decreased with the hood (regardless of water content) compared with no hood.

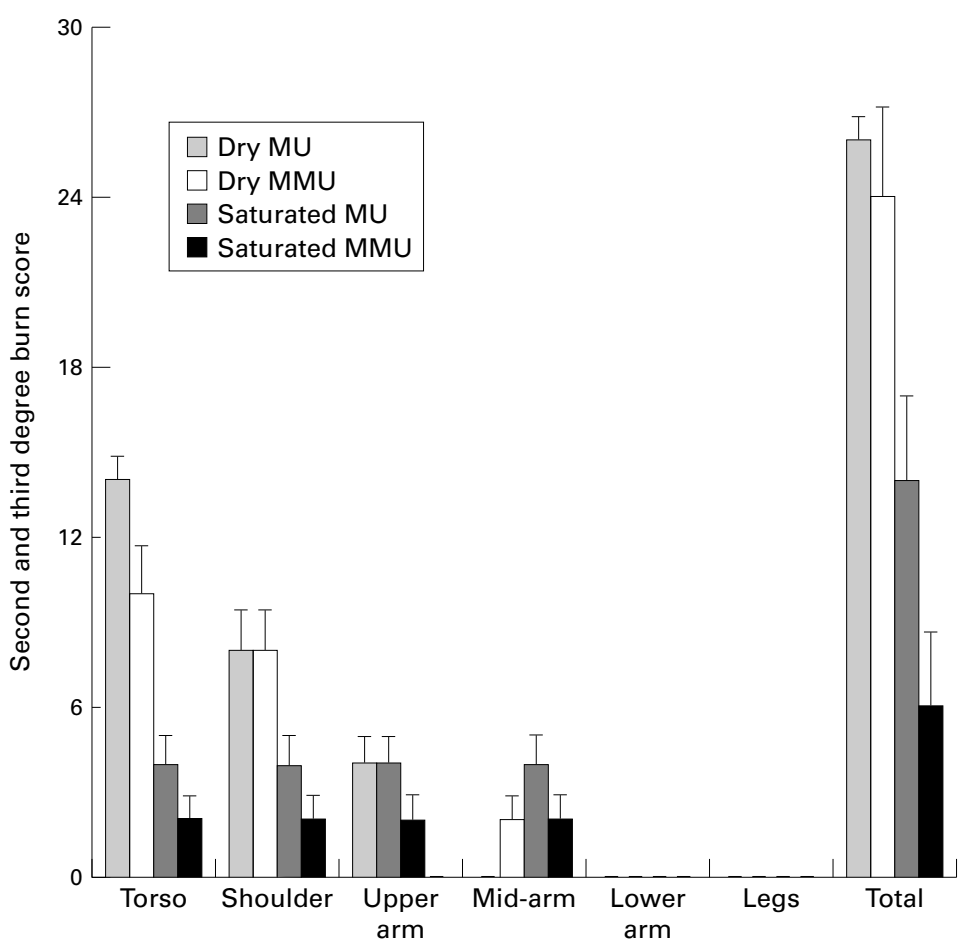

Figure 2 Predicted body burn scores (mean, SD) and their location was measured using PyroMan Thermal Protective Clothing Analysis System following a $2.0 \mathrm{cal} / \mathrm{cm}^{2} / \mathrm{sec}$ exposure for $12 \mathrm{sec}$ under four conditions: dry modern uniform (dry $M U ; n=4)$, dry modified modern uniform (dry $M M U ; n=4)$, saturated modern uniform (saturated $M U ; n=4$, ) and saturated modified modern uniform (saturated $M M U ; n=4)$. Modified modern uniform substitutes cotton shorts and short sleeve T-shirt for long pants and long sleeve shirt made of flame resistant textile ( $60 \%$ polyester $140 \%$ cotton). Burn score for each site equals sum of second degree burns $\times 2+$ sum of third degree burns $\times 3$. For all conditions, no lower arm or leg burns were recorded. There were no significant differences in numbers of burns or burns scores when modern was compared to modified modern uniforms, regardless of water content.
FDNY FIELD RESULTS

Compliance wearing the hood is greatest during the winter months and the modified modern uniform (short sleeve T-shirt and short pants) is worn during non-winter months. A computerized medical database was searched for service connected head burns during the last three winters when hoods were worn [Hood97 (12/1/96$3 / 31 / 97)$, Hood98 (12/1/97-3/31/98), and Hood99 (12/1/98-3/31/99)] and during the last three winters when hoods were not worn: [NoHood93 (12/1/92-3/31/93), NoHood94 (12/1/93-3/31/94), and NoHood95 (12/1/94-3/ 31/95)]. Head burns were analyzed according to four sublocations (scalp includes forehead, face, ears, and neck). FDNY medical computerized database was also searched for service connected upper and lower extremity burns during the summers wearing traditional (5/1/93-8/31/ 93), modern (5/1/95-8/31/95), and modified modern (5/1/98-8/31/98) uniforms. Burn location was further divided into six sublocations: upper leg (above knee), mid-leg (knee to above ankle), lower leg (ankle and below), upper arm (above elbow), mid-arm (elbow to above wrist), and lower arm (wrist and below).

Physicians reviewed all charts and health insurance reimbursement records to determine and verify burn location and severity. In rare cases $(<10 \%)$ when burns involved more than one locations, burns were classified based on location requiring greatest medical leave duration. Thus, for analytical purposes, no firefighter could have more than one burn per fire. Severity indicator was need for hospital admission. Burn depth (second or third degree) was unreliable for analysis due to subjectivity in a health care setting with numerous evaluators. During this study, FDNY fire activity records were reviewed for structural and serious fires. Interestingly, burns only occurred at serious fires. FDNY defines serious fires as an "all hands" fire ( $\geqslant 11$ units with $\geqslant 55$ firefighters responding) or a second or more alarm fire ( $\geqslant 20$ units with $\geqslant 99$ firefighters responding). FDNY medical and fire databases were linked by date, location, and codes to determine distribution of burns per serious fire.

\section{STATISTICAL ANALYSIS}

For each PyroMan test, significant correlations between heat flux and hood condition (none, dry, damp, or saturated) was assessed using Pearson's correlation for continuous variables. Significant differences were assessed by MannWhitney $\mathrm{U}$ tests (non-parametric $t$ tests). Field data (incidence of serious fires and burns by anatomic location) are presented. A KruskalWallis test was used to assess the significance of differences in structural or serious fire distributions among study periods. Distribution of none, one, or two or more burns per serious fire are presented for each period studied as burns per 1000 serious fires. Burn injury per serious fire was analyzed rather than per population at risk because the distribution of serious fires varied among time periods. Numbers of firefighters remained relatively constant (11 110 in 1992, 11433 in 1993, 11436 in 1995, 11315 in 1998, and 11332 in 1999). Mantel-Haenszel $\chi^{2}$ test 
Table 1 Distribution of head burns and rate/1000 serious fires for years with and without FDNY hood

\begin{tabular}{|c|c|c|c|c|c|c|}
\hline & \multicolumn{3}{|l|}{ No hood } & \multicolumn{3}{|l|}{ Hood } \\
\hline & $\begin{array}{l}1993 \\
(n=1356)\end{array}$ & $\begin{array}{l}1994 \\
(n=1471)\end{array}$ & $\begin{array}{l}1995 \\
(n=1411)\end{array}$ & $\begin{array}{l}1997 \\
(n=1288)\end{array}$ & $\begin{array}{l}1998 \\
(n=1118)\end{array}$ & $\begin{array}{l}1999 \\
(n=1292)\end{array}$ \\
\hline \multicolumn{7}{|l|}{ Scalp } \\
\hline 1 Burn & 5 & 8 & 7 & 7 & 9 & 5 \\
\hline$\geqslant 2$ Burns & 0 & 0 & 0 & 0 & 0 & 0 \\
\hline Total & 5 & 8 & 7 & 7 & 9 & 5 \\
\hline Burns/1000 fires & 4 & 5 & 5 & 5 & 8 & 4 \\
\hline \multicolumn{7}{|l|}{ Neck } \\
\hline 1 Burn & 41 & 59 & 51 & 26 & 20 & 20 \\
\hline$\geqslant 2$ Burns & 6 & 11 & 7 & 4 & 4 & 6 \\
\hline Total & 54 & 88 & 68 & 35 & 29 & 32 \\
\hline Burns/1000 fires & 40 & 60 & 48 & $27^{\star}$ & $26^{\star}$ & $25^{\star}$ \\
\hline \multicolumn{7}{|l|}{ Face } \\
\hline 1 Burn & 21 & 23 & 23 & 17 & 13 & 15 \\
\hline$\geqslant 2$ Burns & 2 & 5 & 1 & 2 & 1 & 4 \\
\hline Total & 26 & 34 & 25 & 22 & 15 & 26 \\
\hline Burns/1000 fires & 19 & 23 & 18 & 17 & 13 & 20 \\
\hline \multicolumn{7}{|l|}{ Ears } \\
\hline 1 Burn & 20 & 23 & 10 & 8 & 12 & 2 \\
\hline$\geqslant 2$ Burns & 5 & 7 & 0 & 0 & 1 & 4 \\
\hline Total & 32 & 39 & 10 & 8 & 14 & 10 \\
\hline Burns/1000 fires & 24 & 27 & 7 & $6^{\star}$ & $13^{\star}$ & $8^{\star}$ \\
\hline \multicolumn{7}{|l|}{ Head burn totals } \\
\hline 1 Burn & 80 & 95 & 73 & 50 & 46 & 39 \\
\hline$\geqslant 2$ Burns & 17 & 25 & 14 & 11 & 9 & 16 \\
\hline Total & 117 & 171 & 110 & 72 & 68 & 73 \\
\hline Burns/1000 fires & 86 & 116 & 78 & $56^{\star}$ & $61^{\star}$ & $57^{\star}$ \\
\hline
\end{tabular}

${ }^{\star} \mathrm{p} \leqslant 0.05$ for comparison of firefighter burns/1000 serious fires wearing hoods (all three winters combined) $v$ not wearing hoods (all three winters combined).

was used to test a priori contrasts. Significance defined using an overall type I error of 0.05 and analyzed with Statgraphics software (version 6.1, 1993, STSC Inc, Rockville, Maryland).

\section{Results}

PYROMAN LAB RESULTS

Predicted burn scores were significantly decreased with the hood (regardless of water content) as compared with without the hood (fig 1). This was true for total head score $(p=0.001)$ and for location scores of left and right ear $(p=0.02)$, left and right face $(p=0.001)$, rear neck $(p=0.01)$, and front neck $(p=0.001)$. Hood water content (dry, damp, or saturated) made no significant difference in total head burn score or in location burn scores. Average total burn score without the hood was 12 (range 6 to 14) and decreased by
$91 \%$ to 1 (range 0 to 2 ) with the hood (dry, damp, and saturated conditions). For the uniform (modern $v$ modified modern; dry $v$ saturated) there were no significant differences in predicted burn scores to torso, shoulder, arms, or legs (fig 2). No third burns were recorded when wearing the hood (dry, damp, or saturated) or when wearing modern or modified uniforms (dry or saturated).

FDNY FIELD RESULTS

There were significant differences in distribution of serious fires $(\mathrm{p}=0.05)$ occurring across winters without hoods (mean (SD) 1413 (48)) compared to with hoods (1233 (81)). There were also significant differences in distribution of serious fires $(p=0.024)$ across summers when traditional (1263), modern (1237), and modified modern (983) uniforms were worn. To adjust for this, burns were analyzed based on rates per 1000 serious fires rather than using population based incidence rates.

During the hood study, there were 611 head burns. By anatomic location head burns consisted of neck burns (50\%), face burns (24\%), ear burns $(19 \%)$, and scalp burns $(7 \%)$. The frequency distribution of head burns per serious fire is shown in table 1 . When wearing a hood was compared to not wearing a hood, there were significant decreases in the distribution of neck burns ( $54 \%$ decrease; $\mathrm{p}=0.0001$ ), ear burns $(60 \%$ decrease; $\mathrm{p}=0.0001)$, and head burn totals $(46 \%$ decrease; $p=0.0001)$ per 1000 serious fires (fig 3). Wearing hoods produced no significant differences in the distribution of face burns or scalp burns per 1000 serious fires, because these areas were always completely covered by helmet and SCBA mask. Hospital admissions for head burns were too few for analysis.

During the uniform study, frequency distribution of upper extremity burns per serious fire is shown in table 2 and per 1000 serious fires in fig 4 . With the change from traditional to modern uniform, there was a significant decrease in frequency of upper extremity burns per 1000 serious fires $(86 \%$ decrease; $p=0.001)$. When

Table 2 Distribution of body burns by body region in FDNY firefighters and rate/1000 serious fires

\begin{tabular}{|c|c|c|c|c|c|c|c|c|c|}
\hline & $\begin{array}{l}T U 1993 \\
(n=1263)\end{array}$ & $\begin{array}{l}M U 1995 \\
(n=1237)\end{array}$ & $\begin{array}{l}M M U 1998 \\
(n=983)\end{array}$ & $\begin{array}{l}T U 1993 \\
(n=1263)\end{array}$ & $\begin{array}{l}M U 1995 \\
(n=1237)\end{array}$ & $\begin{array}{l}M M U 1998 \\
(n=983)\end{array}$ & $\begin{array}{l}T U 1993 \\
(n=1263)\end{array}$ & $\begin{array}{l}M U 1995 \\
(n=1237)\end{array}$ & $\begin{array}{l}M M U 1998 \\
(n=983)\end{array}$ \\
\hline & \multicolumn{3}{|l|}{ All burns } & \multicolumn{3}{|c|}{ Upper extremity } & \multicolumn{3}{|c|}{ Lower extremity } \\
\hline 1 Burn & 215 & 47 & 33 & 141 & 26 & 16 & 112 & 13 & 17 \\
\hline 2 Burns & 39 & 4 & 6 & 17 & 0 & 3 & 15 & 0 & 1 \\
\hline$>3$ Burns & 21 & 0 & 3 & 3 & 0 & 1 & 9 & 0 & 1 \\
\hline Total & 362 & 39 & 47 & 186 & 26 & 25 & 176 & 13 & 22 \\
\hline Burns/1000 fires & $\begin{array}{l}287 \\
\text { Upper arm }\end{array}$ & $32^{\star}$ & $48^{\star \star}$ & $\begin{array}{l}147 \\
\text { Mid-arm }\end{array}$ & $21^{\star}$ & $28^{\star \star}$ & $\begin{array}{l}139 \\
\text { Lower arm }\end{array}$ & $11^{\star}$ & $22^{\star \star}$ \\
\hline 1 Burn & $3^{2}$ & 0 & 0 & 7 & 3 & 1 & 137 & 23 & 15 \\
\hline 2 Burns & 0 & 0 & 0 & 0 & 0 & 0 & 14 & 0 & 3 \\
\hline$>3$ Burns & 0 & 0 & 0 & 0 & 0 & 0 & 3 & 0 & 1 \\
\hline Total & 3 & 0 & 0 & 7 & 3 & 1 & 176 & 23 & 24 \\
\hline Burns/1000 fires & $\begin{array}{l}2 \\
\text { Upper leg }\end{array}$ & 0 & 0 & $\begin{array}{l}6 \\
\text { Mid-leg }\end{array}$ & 2 & 1 & $\begin{array}{l}139 \\
\text { Lower leg }\end{array}$ & $19^{\star}$ & $24^{\star \star}$ \\
\hline 1 Burn & 22 & 0 & 3 & 94 & 12 & 15 & 6 & 1 & 1 \\
\hline 2 Burns & 0 & 0 & 0 & 12 & 0 & 0 & 0 & 0 & 0 \\
\hline$>3$ Burns & 0 & 0 & 0 & 9 & 0 & 1 & 0 & 0 & 0 \\
\hline Total & 22 & 0 & 3 & 148 & 12 & 18 & 6 & 1 & 1 \\
\hline Burns/1000 fires & 17 & 0 & 3 & 117 & $10^{\star}$ & $18^{\star \star}$ & 5 & 1 & 1 \\
\hline
\end{tabular}

$\mathrm{TU}=$ traditional uniform $(5 / 1 / 93-8 / 31 / 93) . \mathrm{MU}=$ modern uniform $(5 / 1 / 95-8 / 31 / 95)$.

MMU = modified modern uniform (5/1/98-8/31/98). All burns $=$ trunk + upper + lower extremities

Upper leg $=$ above the knee. Mid-leg $=$ knee to above ankle. Lower leg $=$ ankle and below.

Upper arm $=$ above the elbow. Mid-arm $=$ elbow to above wrist. Lower arm $=$ wrist, hand and fingers.

${ }^{\star} \mathrm{p} \leqslant 0.05$ (MU $v$ TU). ${ }^{\star \star} \mathrm{p} \leqslant 0.05$ (MMU $v$ TU). 


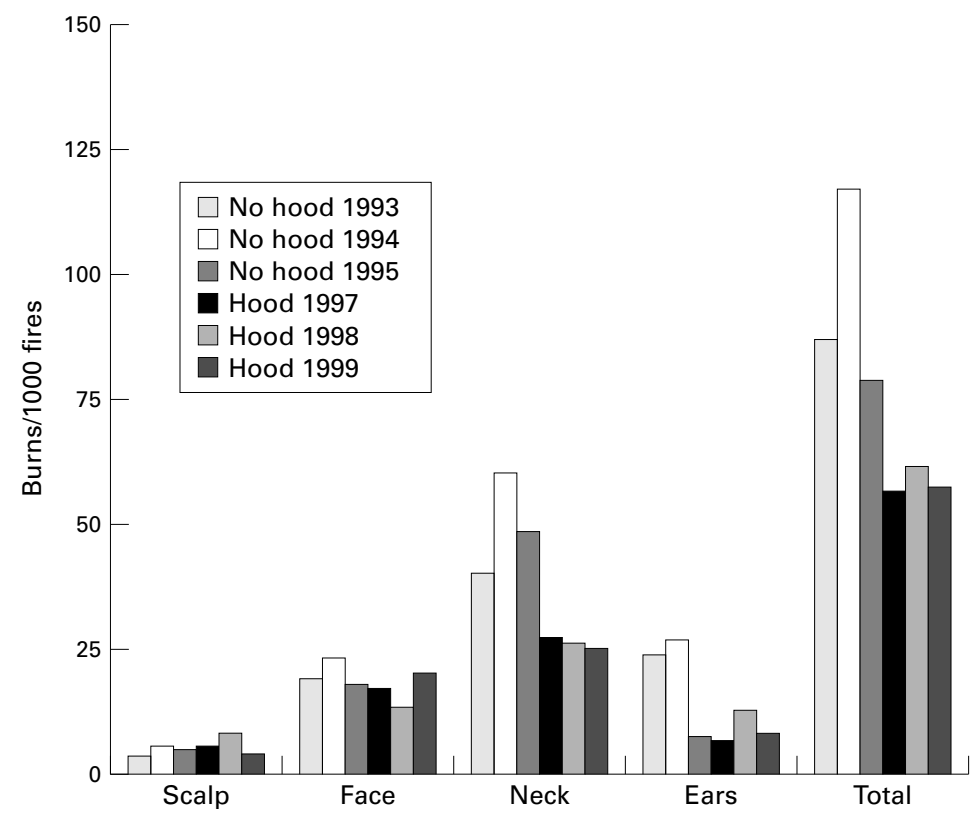

Figure 3 Incidence rates expressed per 1000 serious fires for scalp, face, ear, neck, and total head burns for FDNY firefighters during three successive winters not wearing hood (1993-95) compared with three successive winters wearing hood (1997-99). Wearing a thermal protective hood produced a significant decrease in ear burns (by 60\%), neck burns (by 56\%), and total head burns (by 46\%) but did not significantly affect scalp or face burns. The latter two areas already being covered by the helmet and SCBA face mask.

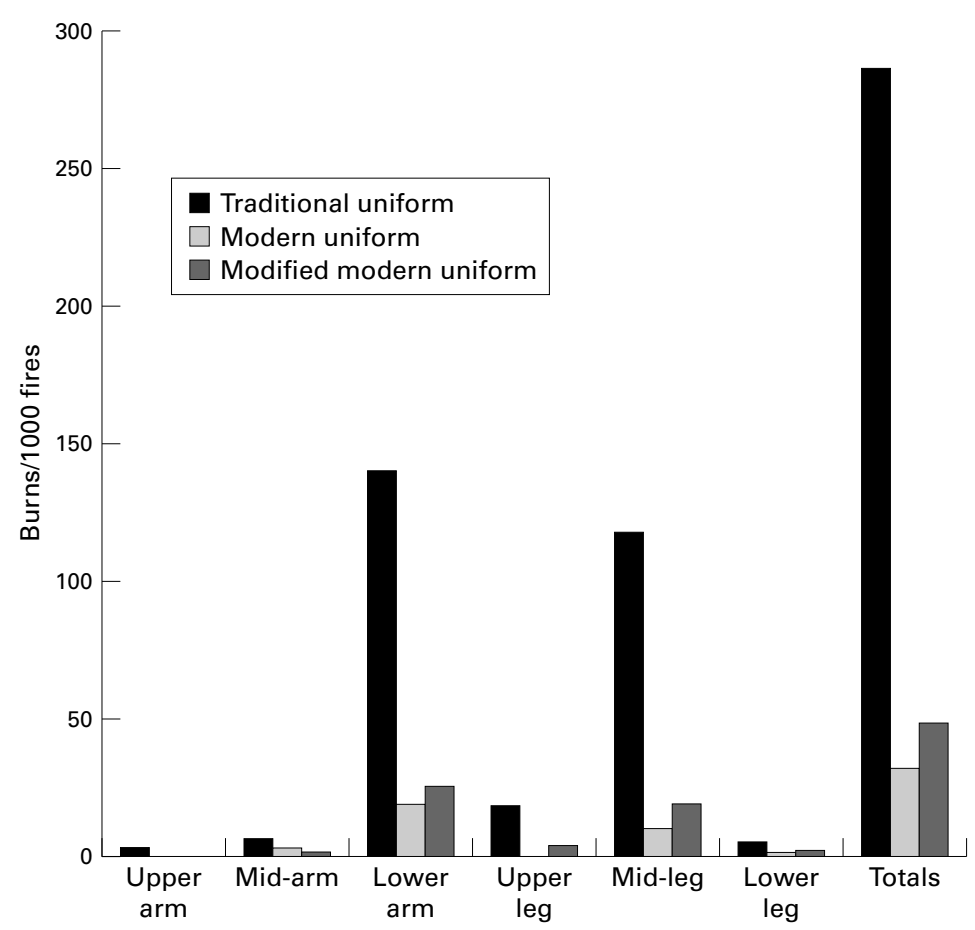

Figure 4 Incidence rates expressed per 1000 serious fires for arm (upper, mid, and lower arm) and leg (upper, mid, and lower) burns for FDNY firefighters during three summers, the first wearing traditional uniform (1993), the second wearing modern uniform (1995), and the third wearing modified modern uniform (1998). With the change from traditional to modern uniform, there were significant decreases in lower arm burns by 87\%, in mid-leg burns by $92 \%$ and in total burns by $89 \%$. No significant differences in burn injuries were found with the change from the modern to modified modern uniform. modern was compared to modified modern uniform, there was no significant difference in frequency of upper extremity burns per 1000 serious fires $(p=0.620)$. Throughout all periods, the majority of upper extremity burns occurred to the lower arm (94\%). With the change from traditional to modern uniform, there was a significant decrease in frequency of lower arm burns per 1000 serious fires $(87 \%$ decrease; $p=0.001)$. With the change from modern to modified modern uniform, there was no significant difference in frequency of lower arm burns per 1000 serious fires $(\mathrm{p}=0.467)$. Upper arm and mid-arm burns were too few for analysis. The frequency distribution of lower extremity burns per serious fire is shown in table 2 and per 1000 serious fires in fig 4 . With the change from traditional to modern uniform, there was a significant decrease in frequency of lower extremity burns per 1000 serious fires ( $93 \%$ decrease; $\mathrm{p}=0.001)$. When modern was compared to modified modern uniform, there was no significant difference in frequency of lower extremity burns per 1000 serious fires $(p=0.051)$. The majority of lower extremity burns occurred to the anterior mid-leg $(84 \%)$. With the change from traditional to modern uniform, there was a significant decrease in frequency of mid-leg burns per 1000 serious fires (92\% decrease; $\mathrm{p}=0.001$ ). With the change from modern to modified modern uniform, there was no significant difference in frequency of mid-leg burns per 1000 serious fires $(p=0.168)$. Upper leg and lower leg burns were too few for analysis. For comparison between modern and modified modern uniforms, hospital admissions were too few for analysis.

\section{Discussion}

Annual occupational injury and fatality surveys in the United States show firefighter injury rates to be higher than those of any other workforce and line-of-duty fatality rates ranking within the top five occupations. ${ }^{9}{ }^{10}$ For firefighters, burns are consistently among the top three causes of injury. ${ }^{11} 12$ Our prior studies have shown that the modern uniform produced substantial reductions in upper and lower extremity burn injuries. ${ }^{5}{ }^{13} 14$ In this current study both laboratory and FDNY field results demonstrate (1) dramatic reductions in head burns when wearing a thermal protective hood and (2) show that wearing a modified modern uniform (short sleeved T-shirt and short pants worn underneath) does not reduce thermal protection to the upper and lower extremities. No laboratory test can completely predict field results where exposures and conditions are varied and complicated but given the extreme hazards of firefighting, field testing is ethically impossible without first determining if thermal protection is acceptable under laboratory conditions. Our study is unique in several respects.

PyroMan with hood predicted no third degree head burns and found second degree head burns were nearly eliminated (fig 1). PyroMan found no significant differences in thermal protection when the modified modern 
was compared to the modern uniform and also found no third degree body burns at any location and no second degree leg burns (fig 2). The advantage of using PyroMan to assess thermal protective performance is that the entire uniform ensemble can be evaluated under realistic wear and fit spatial conditions under the combined influence of helmet with earflaps turned down, SCBA mask, and protective overcoat with collar turned up. PyroMan tests complement laboratory bench tests where the relative performance of a hood swatch is evaluated in isolation under mounted conditions. Modern firefighting uniforms derive thermal protection not only from the characteristics of a single layer of material or single garment but from interactions between multiple layers and protective garments. PyroMan is not without limitations. In addition to its inability to test low to moderate level heat flux exposures, PyroMan can only be positioned upright. Firefighters are taught to remain as low to the ground as possible during firefighting. Position and repeated compression (knee against floor) may affect location and intensity of thermal exposure. Also, the uniform ensemble tested, while including the SCBA mask, did not include the SCBA tank and harness. Financial and safety considerations prevented this. This may have affected reflection of thermal energy towards the head and shoulders.

An important aspect of this study is the evaluation of water content on thermal protective performance. A major concern for firefighters has been whether water content (wet $v$ dry) affects thermal protection. The perception being that wet hoods and uniforms lead to burns. Burns occur when the rate of heat transfer to skin exceeds the skin's ability to dissipate heat through circulation, conduction, convection, and evaporation. The uniform affords thermal protection by absorbing, inhibiting, and reducing the rate of heat transfer from external fire environment to skin. The hood's porous weave allows air and water to be contained within and about its fibers. Compared with water, air is an excellent insulator, markedly reducing the rate of heat transfer to the skin. As hood water content increases the amount of air trapped within the hood decreases, thus elevating its conductive potential. Yet, the overall effect of increasing water content is more complicated. As water content increases, mass increases so that wet hoods and uniforms store greater amounts of heat energy before transferring that energy to the skin. In contrast to the uniform, evaporation of water from the hood should transfer heat energy back to the external environment. These three mechanisms compete in the overall heat transfer process. Our data show that thermal protection actually improved as water content increased during simulated flashover exposure. Current NFPA guidelines test hood and uniform thermal protection only under dry conditions. ${ }^{1}$ It must be stressed that under realistic conditions the thermal protective performance of a dry hood and uniform is irrelevant since a firefighter fighting fires is never dry. Water content in the hood is relatively easy to determine and reproduce. What remains to be determined is the exact amount and location of water in the uniform and the effect of lower level heat flux exposures.

The final and true evaluation of a uniform's thermal protective properties is its field performance. This study demonstrates the high level of thermal protection afforded FDNY firefighters by the hood and modern uniform. Wearing the hood, head burn totals decreased by $46 \%$, of which neck burns decreased by $54 \%$ and ear burns decreased by $60 \%$ (table 1 ). Thermal protection from the modern uniform was so great that the impact of clothes worn underneath (modern $=$ long sleeve shirt and long pants; modified modern $=$ shirt sleeve T-shirt and short pants) was insignificant (table 2 ). It is notable that after changing from traditional to modern or modified modern uniforms, upper and lower leg burns have dramatically decreased to about one per month, but burn severity remains a critical issue.

A major strength of this study is the entire workforce, rather than an artificially created sample, was used to study the effect of uniform modifications on burns. By studying the entire workforce, issues such as selection bias and differences in tenure, training, and fire experience, become irrelevant. Yet, because comparisons were not run concurrently this study does have potential limitations. There were small but significant decreases in serious fires. Because our analysis was based on frequency distribution of burns per fire, rather than the incidence of burns, our results accurately reflect the hood or uniform change rather than the decrease in serious fires. This analysis requires the assumption that the number of firefighters fighting serious fires did not decrease over time. In fact, with the introduction of modern uniform, modified modern uniform and hood, the number of FDNY firefighters per fire actually increased because of concerns that modern uniforms may produce greater physiologic stress. An increase in firefighters per serious fire would only lead to our underestimating the impact of modern protective uniforms and hoods on burn injuries.

In conclusion, laboratory tests showed that thermal protection was: (1) dramatically improved by the hood with protection increasing as water content increased and (2) not significantly different between modern and modified modern uniforms, regardless of water content. FDNY field results confirmed these tests showing (1) significant decreases in neck burns (by $54 \%$ ), ear burns (by $60 \%$ ), and head burn totals (by $46 \%$ ) wearing the hood and (2) no significant differences in upper or lower extremity burns wearing modern versus modified modern uniforms. Based on combined laboratory and field results, we strongly recommend the use of modern thermal protective hoods to reduce burns and the modified modern uniform to improve comfort and work capacity without sacrificing thermal protection. $^{15}$ 
This study would not have been possible without the commitment of the FDNY Fire Commissioner, the Uniformed Firefighters Association, the Uniformed Fire Officers Ass
ation, and a core group of FDNY firefighters and officers.

1 National Fire Protection Association. 1971 Standard on protective clothing for structural fire fighting. Quincy, MA: NFPA, tective 1997.

2 Lawson RJ. Thermal performance and limitations of bunker gear. Fire Engineering 1998;12:37-56.

3 Gempel F, Burgess WA. Thermal environment during structural fire fighting. NFPCA grant No 76010. Washington DC: National Fire Prevention and Control Administration, 1977.

4 Krasny JF, Sello SB. Fibers and textiles. Fire protection handbook. 16th Ed. Quincy, MA: National Fire Protection Association, 1986: 5-27.

5 Prezant DJ, Kelly KJ, Malley KS, et al. Impact of a modern firefighting protective uniform on the incidence and severMed 1999;41:469-79.

6 Stoll AM, Chianta MA. Heat transfer through fabrics as related to thermal injury. Transactions of the New York Acadrelated to thermal injury. Transactions of the
emy of Science, Series 3 1971;33:649-70.

emy of Science, Series 3 1971;33:649-70.
7 Pawar M. Analyzing the thermal protective performance of single layer garment materials in bench scale and manikin tests. gle layer garment materials in bench scale and manikin tests.
(Doctoral dissertation.) Raleigh, NC: North Carolina State (Doctoral disserta

8 Dale JD, Crown EM, Ackerman MY, et al. Instrumented manikin evaluation of thermal protective clothing. In:
McBriarty JP, Henry NW, eds. Performance of protective clothing. Vol 4. Philadelphia, PA: American Society of Testing and Materials, 1992: 717-34.

9 US Department of Labor. Survey of occupational injuries and illnesses. Washington, DC: US Bureau of Labor Statistics, 1996. (US Department of Labor Summary 98-1.)

10 US Department of Labor. National census of fatal occupaStatistics, 1998. (US Whington, DC: US Bureau of Labor

11 International Association of Fire Fighters. 1989 Firefighter death and injury survey. Washington, DC: International death and injury survey. Washington.

12 International Association of Fire Fighters. 1998 Firefighter death and injury survey. Washington DC: International death and injury survey. Washingt

13 Prezant DJ, Barker RL, Bender M, et al. Predicting the impact of a design change from modern to modified modern firefighting uniforms on burn injuries using manikin fire tests. In: Nelson CN, Henry NW, eds. Performance of protective clothing: issues and priorities for the 21st century. West Conshohocken, PA: American Society for Testing and Materials, 2000;7:224-33.

14 Prezant DJ, Freeman K, Kelly KJ, et al. Impact of modern and modified modern firefighting uniforms on burn prevention outcomes in New York City firefighters. F Occup Environ Med 2000;42:827-34.

15 Malley KS, Goldstein AM, Aldrich TK, et al. Effects of fire fighting uniform (modern, modified modern and traCity firefighters. F Occup Environ Med 1999;41:1104-15. 